\title{
INFORMALIDADE E DIFERENCIAÇÃO DE RENDIMENTO ENTRE OS SETORES FORMAL E INFORMAL PARA A REGIÃO METROPOLITANA DE BELÉM
}

\section{Resumo}

Leandro Batista Duarte1 Jader Fernandes Cirino2 Ana Beatriz Pereira Sette3

O presente estudo teve como objetivo analisar a diferença de rendimento entre trabalhadores formais e informais na Região Metropolitana de Belém. Para tanto, foi definido como setor informal os trabalhadores que se autodeclararam por conta própria, exceto as ocupações de profissionais liberais, e os empregados sem carteira assinada. Por outro lado, o setor formal ficou constituído pelos empregados assalariados com carteira assinada (domésticos ou não), funcionários públicos e militares, empregadores e profissionais liberais. Na metodologia, foi utilizada a equação minceriana estimada pelo método de regressão quantílica, apresentado originalmente por Koenker e Basset (1978). Em relação ao modelo de regressão quantílica, observou-se tanto para os trabalhadores formais quanto para os informais, a relevância da variável educação como importante determinante para 0 rendimento do trabalho, ou seja, quanto maior o ano de estudo maior esse último.

Palavras-chave: Mercado de Trabalho; Regressão Quantílica; Discriminação de rendimento; RMB

Classificação JEL: J31; J71; C01

\section{INFORMALITY AND INCOME DIFFERENTIATION BETWEEN FORMAL AND INFORMAL SECTORS FOR THE METROPOLITAN REGION OF BELÉM}

\begin{abstract}
This study aimed to analyze the yield difference between formal and informal workers in the metropolitan region of Belém. Thus, it was defined as informal sector workers declared themselves on their own, except liberal occupations, and employees without formal contract. On the other hand, the formal sector was made up of salaried employees with a formal contract (domestic or not), civil and military officials, employers and professionals. The methodology was

1 Doutorando em Economia pela Universidade Federal de Pernambuco (UFPE). Mestre em Economia pela Universidade Federal de Viçosa (UFV). Graduação em Economia pela Universidade Estadual de Santa Cruz (UESC). Email: leandro.duarte1@hotmail.com

2 Doutor em Economia Aplicada pela Universidade Federal de Viçosa. Professor Adjunto do Departamento de Economia da Universidade Federal de Viçosa.

3 Mestranda em Economia Aplicada e Graduação em Economia pela Universidade Federal de Viçosa. Email: anabeatriz.sette@gmail.com
\end{abstract}


used to mincerian equation estimated by quantile regression method, originally presented by Koenker and Basset (1978). Regarding the quantile regression model, it was observed both for formal workers and for the informal, the relevance of variable education as an important determinant for the performance of work, ie, the higher the year of further study the latter.

Keywords: Labour market; Quantile regression; income discrimination; RMB JEL Classification: J31; J71; C01

\section{Introdução}

A informalidade no Brasil ganha importância a cada dia. Além do grande número de trabalhadores informais existente hoje, este número vem crescendo ao longo do tempo. A cada ano é menor o percentual de trabalhadores que contribui para instituto de previdência e que possui carteira de trabalho assinada. Se for verdadeira a ideia de que os salários no setor informal são menores que os do setor formal, então existirá um contingente cada vez maior de trabalhadores com remuneração mais baixa. Além disso, os trabalhadores do setor formal, protegidos pela lei, conseguem vantagens trabalhistas não acessíveis aos trabalhadores do desregulamentado setor informal, o que resulta na ampliação do diferencial de salários entre os dois grupos (MENEZES-FILHO, MENDES e ALMEIDA, 2004).

A grande maioria dos brasileiros que trabalham no mercado informal não dispõe de proteções de leis trabalhistas ou previdenciárias. A desproteção do mercado informal é um fenômeno preocupante, tratando-se de uma forma de exclusão social. A desproteção gerada pela informalidade atinge as finanças públicas, de maneira mais direta, a Previdência Social, criando déficit. $O$ financiamento desse déficit através de empréstimos junto ao sistema financeiro tem um impacto dramático na elevação da taxa de juros o que, por sua vez, desestimula os investimentos e inibe a geração de empregos. Os estragos da informalidade atingem toda a sociedade, sendo que uma parcela expressiva do desemprego atual decorre da falta de investimentos, por isso, informalidade tem muito a ver com o desemprego (PASTORE, 2004).

Esse crescimento da informalidade, ou seja, dos trabalhos sem proteções legais, deve-se, em parte, ao abuso de empregadores que, prevalecendo-se de um excesso de mão de obra existente no mercado de trabalho do Brasil, em especial, de pessoas de pouca qualificação, contratam trabalhadores sem observar os mandamentos legais. Mas isso se deve também ao caráter extremamente rígido e complexo da legislação atual. Estudos realizados pelo Banco Mundial em mais de 100 países mostram que o Brasil possui uma das legislações trabalhistas mais complexas e mais rígidas do mundo.

Além do mais, na perspectiva do trabalhador, aspectos econômicos e/ou socioculturais podem justificar a entrada na informalidade. Uma abordagem de cunho econômico tem a concepção de que perante as grandes dificuldades e 
empecilhos de encontrarem vagas de emprego no setor formal, os trabalhadores seriam obrigados a sujeitarem a qualquer tipo de atividade para sobreviver. Sob esta ótica, pode-se considerar o trabalho informal como estratégia de sobrevivência. Outra abordagem é a de cunho social, que de acordo com Ferreira (2007), considera o exercício de atividades informais, as formas de organização informal da produção, como uma escolha consciente da maioria dos componentes do setor. O trabalho informal sob este prisma pode ser considerado como alternativa de vida, pois o trabalhador estaria em busca de liberdade de agir, de jornadas de trabalho mais flexíveis (possibilidade de fazer o próprio horário), controle do próprio negócio tendo a inexistência da figura do chefe, acesso a uma parcela de rendimentos, ou até mesmo melhores condições de trabalho e remuneração que muitos, anteriormente, no setor formal, não possuíam. Desta forma, com o aparecimento de novas formas de trabalho precário e a redução dos empregos no mercado formal, os trabalhadores passaram a atuar no setor informal (PEREIRA; SILVA e SILVA, 2014).

De acordo com o Dieese/PA, mais de 400 mil pessoas trabalham no setor informal na Região Metropolitana de Belém (RMB), sendo 240 mil somente na capital, que é de $59,9 \%$ do pessoal ocupado. As principais causas do crescimento da economia informal na Região Metropolitana de Belém são o desemprego e a falta de qualificação profissional.

O crescimento acentuado do setor informal na RMB é, em parte, consequência direta tanto da migração rural quanto do deslocamento de trabalhadores de outros estados e regiões do país, e resultado do processo de "reestruturação produtiva" que hoje afeta a economia mundial, deve também levar em consideração as estratégias operacionalizadas pelos novos moradores da cidade, que procuram e encontram, através das conexões disponíveis, alguma inserção no mercado de trabalho local. Essas conexões articulam pessoas que já estão no setor informal, e essa dinâmica de inserção tende a ampliar o número de novos integrantes (RODRIGUES e BORGES, 2012).

A RMB concentra grande contingente populacional (em boa parte, imigrantes), sem, contudo, oferecer-lhes condições de inserção no mercado de trabalho, em bases dignas, uma vez que sua estrutura produtiva, assentada no setor terciário, implica uma baixa capacidade de alavancagem endógena do desenvolvimento. Como resultado, ganham reforço outras mazelas, características de grandes zonas urbanas, a exemplo do crescimento vertiginoso de áreas de invasão, concentrando geralmente grandes bolsões de pobreza (PINHEIRO e ÁLVARO, 2006).

Com base na relevância assumida por este contexto na atualidade, pode-se levantar uma problemática central a ser investigada neste artigo: há diferença de rendimento entre trabalhadores formais e informais na Região Metropolitana de Belém? Busca-se verificar se os padrões de incorporação dos trabalhadores na informalidade da RMB apresentam diferenças acentuadas quando se trata de setor formal e informal.

A apreensão dessas nuanças pode se constituir num instrumento útil para o desenho de políticas voltadas ao setor informal, que levem em conta a questão de discriminação. $O$ fato da RMB se constituir em um forte polo de 
imigração e a relativa carência de estudos sobre a região contribui para motivar sua escolha como objeto de estudo.

O presente artigo está estruturado em cinco seções, incluindo esta introdução. Na segunda, faz-se uma caracterização sobre a Região Metropolitana de Belém. Na terceira seção, é apresentada a metodologia adotada e também as escolhas feitas em termos de fonte de dados para a análise proposta. Em seguida, é feita uma análise do modelo estimado. Por fim, são tecidas as considerações finais, seguidas das referências.

\section{Caracterização da Região Metropolitana de Belém ${ }^{4}$}

A Região Metropolitana de Belém, criada pela Lei Complementar Federal em 1973 é uma conurbação com 2.360.250 habitantes segundo a estimativa populacional de 2013 do IBGE. Grande Belém, como também é conhecida, em 2013 era a 10 área metropolitana mais populosa do Brasil e a $177^{a}$ do mundo, além de ser a mais populosa da Região Norte. O núcleo da RMB é composto pelos seguintes municípios: Ananindeua, Belém, Marituba, Benevides, Santa Isabel do Pará, Santa Bárbara do Pará e Castanhal. Em 2011 a RMB sozinha concentrava aproximadamente $40 \%$ da riqueza e $35 \%$ da população de todo o estado do Pará, em pouco mais de $2 \%$ de território (IBGE, 2015).

A economia na cidade de Belém baseia-se principalmente nas atividades do comércio, serviços e turismo, embora seja também desenvolvida a atividade industrial com grande número de indústrias alimentícias, navais, metalúrgicas, pesqueiras, químicas e madeireiras. Historicamente, a Região Metropolitana de Belém, constitui-se na principal via de entrada na região norte do Brasil, com uma posição geográfica privilegiada (FERREIRA, 2003).

Belém tem tradicionalmente concentrado empregos e serviços, e funcionado como polo de atratividade tanto na Região Metropolitana, inicialmente composta pelos municípios de Belém e Ananindeua, como na sua composição atual, ocasionando aumento populacional significativo nos municípios mais próximos do polo. Os principais diferenciais de Belém em relação aos demais municípios da $\mathrm{RMB}$ e do Estado do Pará são: a oferta de serviços de saúde, educação e a economia baseada na prestação de serviços constituídos para o funcionamento de projetos econômicos no restante do Estado.

A agricultura da Região Metropolitana de Belém baseia-se no cultivo de laranja, banana, cana-de-açúcar, coco, arroz, mandioca, cacau, feijão e, principalmente, pimenta-do-reino, cujo estado é o maior produtor nacional. A pecuária é mais desenvolvida na porção sudoeste do Pará, onde o rebanho bovino é de aproximadamente 14 milhões de cabeças de gado. Também há

\footnotetext{
${ }^{4}$ Essa caracterização foi elaborada com base nas referências: IBGE (2015); Ferreira (2003); Ministério do Trabalho e Emprego.
} 
criações de aves, suínos, equinos e bubalinos, esse último é mais comum na ilha de Marajó.

O setor industrial concentra-se na Região Metropolitana de Belém. Os principais segmentos industriais são o madeireiro, alimentício, químico, alumínio, entre outros. O extrativismo mineral é a principal atividade econômica do Pará. Esse segmento baseia-se na exploração da bauxita, ferro, manganês, calcário, ouro, estanho. O alumínio e o minério de ferro são os principais produtos de exportação. O extrativismo vegetal também é de grande importância como a madeira e a castanha-do-pará.

Com relação ao mercado de trabalho, em uma década, entre 2003 e 2013, acompanhando o crescimento populacional dos municípios, a População Economicamente Ativa (PEA) da Região Metropolitana de Belém (RMB) cresceu $13 \%$, atingindo dois milhões de pessoas. Ao mesmo tempo, a taxa de desemprego da Região diminui de $9,5 \%$ para 3,5\%. Em 2003, a taxa de desemprego oculto por desalento foi de $2 \%$, no Estado do Pará.

Quatro anos depois, em 2007, o percentual chegou a 1,1\%. A taxa de desemprego oculto por precariedade também caiu de 3,6\% para 1,4\%, de 2003 a 2013. O desemprego oculto pelo desalento está relacionado às pessoas que não possuem trabalho e nem procuraram ocupação nos últimos 30 dias. Desempregados pelo trabalho precário são aqueles que, para sobreviver, exerceram algum trabalho de auto-ocupação, de forma descontinua e irregular.

O nível de ocupação da RM belenense subiu de 1,5 milhão para 1,9 milhão de cidadãos, em uma década. Em 2006, segundo o Ministério do Trabalho e Emprego (MTE), o número de paraenses que conseguiram ingressar no mercado foi de 221.093. No ano de 2013, a quantidade de empregados, em 12 meses, subiu em mais de 10 mil pessoas, chegando 361.589 , contra 349.231 desligamentos - saldo de, aproximadamente, 12 mil novos empregos em 365dias.

\section{Metodologia e Modelo Econométrico}

No presente estudo, utiliza-se o conceito de informalidade proposto por Machado, Oliveira e Antigo (2008) o qual combina a definição de regulação do trabalho, ou seja, carteira assinada como característica de formalidade e sem carteira assinada como informalidade, e a definição de subordinação. Esta abordagem consiste em analisar a esfera produtiva em geral, tendo em vista que a atividade capitalista não preenche todo o espaço econômico existente, deixando portas abertas para a inserção intersticial do setor informal de forma subordinada (CACCIAMALI, 2000). No mesmo sentido, conforme apresentado originalmente por OIT (1972), o setor informal englobaria aquelas atividades não incorporadas pela atividade capitalista, dado que a lucratividade daquelas não seria compatível com as exigências mínimas dessa última. Dessa forma, a informalidade englobaria a pequena unidade de produção onde não ocorre a separação entre os proprietários dos meios de produção e o processo de trabalho. A escolha por tal conceito deve-se ao fato de ser atual e mais adequado para tentar diferenciar melhor os setores. 
Então, combinando as duas definições anteriores estabeleceram-se como informal os trabalhadores que se autodeclararam por conta própria, exceto as ocupações de profissionais liberais, e os empregados sem carteira assinada. Por outro lado, o setor formal ficou constituído pelos empregados assalariados com carteira assinada (domésticos ou não), funcionários públicos e militares, empregadores e profissionais liberais.

Quanto ao modelo estimado, as equações mincerianas do presente artigo foram estimadas utilizando 0 método de regressão quantílica, apresentado originalmente por Koenker e Basset (1978). A opção por tal metodologia ocorreu devido ao interesse de analisar o impacto dos regressores em diversos pontos da distribuição do regressando - rendimento do trabalho no presente estudo - e não apenas em um ponto médio desse último, como fornecido pelo método dos Mínimos Quadrados Ordinários. Formalmente, um modelo geral de regressão quantílica para os rendimentos pode ser representado por:

$$
\ln w_{i}=x_{i} \beta_{\theta}+\varepsilon_{\theta i} ; \operatorname{com} Q u a n t_{\theta}\left(\ln w_{i} \mid x_{i}\right)=x_{i} \beta_{\theta}
$$

onde $\ln w_{i}$ é o logaritmo natural do rendimento/hora do indivíduo, xi é um vetor de variáveis explicativas e $\beta_{\theta}$ é um vetor de parâmetros a ser estimado. Quant $_{\theta}\left(\ln _{\mathrm{i}} \mid \mathrm{x}_{\mathrm{i}}\right)=\mathrm{x}_{\mathrm{i}} \beta_{\theta}$ denota o quantil condicional de $\ln w_{\mathrm{i}}$ dado $\mathrm{x}$, onde $\theta \in(0,1)$ é definida como sendo a solução do seguinte problema de minimização:

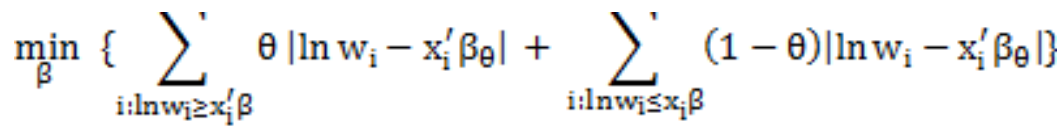

que é o mesmo que minimizar:

$$
\min _{\beta}\left\{\sum \rho_{\theta}\left(\ln w_{i}-x_{i}^{\prime} \beta_{\theta}\right)\right\}
$$

em que $\rho$ é uma check function definida por:

$$
\rho_{\theta}\left(\xi_{1}\right)=\left\{\begin{array}{l}
\theta \xi_{\text {p para }} \xi \geq 0 \\
(1-\theta) \xi_{\text {p }} \text { para } \xi \leq 0
\end{array}\right.
$$

onde a função $\rho_{\theta}$ multiplica os resíduos por $\theta$ se eles forem não-negativos, $\mathrm{e}$ por $(1-\theta)$ caso contrário, para que, desta forma, sejam tratados assimetricamente. Assim, o $\theta$ pode ser obtido para os diversos quantis ao longo da distribuição.

De modo a verificar se os coeficientes estimados de fato diferem entre 
os quantis, justificando assim o uso do modelo de regressão quantílica, são aplicados testes de Wald para os parâmetros de todos os quantis de cada variável.

Dado o objetivo de estimar as diferenças nos retornos em termos de rendimentos para os atributos dos trabalhadores formais e informais, para diferentes níveis da distribuição de tal variável, o presente trabalho utilizou o seguinte modelo:

$$
\begin{aligned}
\ln w_{i}= & \beta_{0}^{\theta}+\beta_{1}^{\theta} E_{2 i}+\beta_{2}^{\theta} E_{3 i}+\beta_{3}^{\theta} E_{4 i}+\beta_{4}^{\theta} E_{5 i}+\beta_{5}^{\theta} I d a_{i}+\beta_{6}^{\theta} I d a_{i}^{2}+\beta_{7}^{\theta} R_{1 i}+ \\
& \beta_{8}^{\theta} R_{2 i}+\beta_{9}^{\theta} S_{1 i}+\beta_{10}^{\theta} S_{2 i}+\beta_{11}^{\theta} S_{3 i}+\beta_{12}^{\theta} S_{4 i}+\varepsilon_{\theta i}
\end{aligned}
$$

onde $\beta_{i}^{\theta}$ são os parâmetros estimados para o quantil $\theta(10,50,90)^{5}$ da variável dependente, que nesse caso é o logaritmo dos rendimentos do trabalho, In $w_{i}$; $E_{k}(k=2, \ldots, 5)$ são variáveis discretas que indicam a escolaridade do trabalhador, em anos de estudo, com o grupo base formado por trabalhadores com 0 a 3 anos de estudo, $E_{2}, E_{3}, E_{4}$ e $E_{5}$, respectivamente, por trabalhadores com 4 a 7, 8 a 10, 11 e mais de 11 anos de estudo; Ida representando a idade do trabalhador como proxy da experiência; $R_{m}(m=1,2)$ são variáveis dummies que indicam a raça do trabalhador, com o grupo base sendo formado por brancos, $R_{1}$ assumindo o valor 1 para negros e 0 , caso contrário, e $R_{2}$ assumindo o valor 1 para pardos e zero, caso contrário; $S_{k}(k=1, \ldots, 4)$ são variáveis dummies que indicam o setor de atividade do trabalhador, sendo 0 grupo base formado pela indústria, $S_{1}$ representando construção, $S_{2} 0$ comércio, $S_{3}$ a administração pública e $S_{4}$ os serviços; e $\varepsilon_{\theta i}$ representa os resíduos da regressão.

As variáveis relacionadas às características dos indivíduos e de suas localidades, que não dizem respeito diretamente ao capital humano, foram incluídas seguindo a sugestão de Borjas e Mincer (1976). Diversos outros trabalhos seguem a mesma linha, como Pianto e Pianto (2002), Carneiro e Henley (2001), Machado, Oliveira e Antigo (2008) e Cirino e Lima (2012).

É importante destacar que a equação (5) foi estimada separadamente para trabalhadores formais e informais do sexo masculino entre 24 e 65 anos de idade na Região Metropolitana de Belém com o objetivo de se obter comparações nos retornos dos rendimentos às variáveis do modelo ao longo dos quantis de sua distribuição. Além disso, destaca-se que a estimativa foi feita utilizando o software Stata 12 incorporando os pesos amostrais dos indivíduos disponíveis nos microdados da PNAD 2013.

\subsection{Fonte de Dados}

A PNAD é realizada por meio de uma amostra probabilística de domicílios obtida em três estágios de seleção: unidades primárias, municípios;

${ }^{5}$ Foram escolhidos tais quantis com o intuito de observar o rendimento nos extremos e no meio da distribuição de rendimentos.

${ }^{6}$ PNAD mais recente disponível no momento em que foi feita a pesquisa. 
unidades secundárias, setores censitários; e unidades terciárias, unidades domiciliares (domicílios particulares e unidades de habitação em domicílios coletivos).

Em 2013, a PNAD abrangeu um total de 362.555 indivíduos em 148697 famílias, distribuídos em 1.100 municípios (IBGE, 2013). Como o foco é a comparação entre os setores, serão considerados os trabalhadores do sexo masculino, evitando-se possíveis distorções causadas pela diferenciação existente entre o mercado de trabalho para homens e mulheres e pelo problema de seletividade amostral. Sobre este último, como a quase totalidade dos homens está no mercado de trabalho, este problema é irrelevante quando se estima a equação de rendimentos para trabalhadores (DALBERTO, 2014).

Portanto, os dados do presente trabalho foram obtidos da PNAD para o ano de 2013, sendo a amostra utilizada constituída por homens entre 24 e 65 anos de idade no mercado de trabalho urbano da região metropolitana de Belém. A escolha de tal faixa etária se deu de modo a excluir do recorte os trabalhadores jovens e os possíveis aposentados.

\section{Análise descritiva da Região metropolitana de Belém}

$\mathrm{Na}$ Tabela 1, as estatísticas descritivas da amostra considerada são abordadas por segmento no mercado de trabalho, contendo a média e o desvio-padrão das variáveis contínuas e as proporções por categoria das variáveis discretas.

Ao observar a variável renda, percebe-se uma substancial diferença de rendimentos entre trabalhadores formais e informais, sendo que o primeiro grupo apresenta um rendimento maior. Quanto à escolaridade, nota-se diferença entre ambos os grupos, com os trabalhadores formais possuindo, em média, cerca de $(2,2)$ anos a mais de estudo do que os informais. Em relação à idade média, verifica-se que esta é maior para os trabalhadores informais, sendo a diferença entre os setores de 3,61 anos.

Em relação às características raciais, em termos gerais, observou que os pardos e os brancos são a maioria tanto no setor formal quanto informal.

Tabela 1 - Estatísticas descritivas para os trabalhadores formais e informais da $\mathrm{RMB}, 2013$

\begin{tabular}{lcccc}
\hline \multirow{2}{*}{ Variável } & Média & $\begin{array}{c}\text { Formais } \\
\text { Desvio-padrão }\end{array}$ & \multicolumn{2}{c}{ Média } \\
& & & & \\
& $\mathrm{R} \$ 1.710,69$ & 83,62 & $\mathrm{R} \$ 1.260,73$ & 55,34 \\
Renda & 10,13 & 0,13 & 7,93 & 0,16 \\
Escolaridade & 39,24 & 0,34 & 42,85 & 0,47 \\
Idade & Proporção & Proporção \\
\hline Categorias & 0,1110 & 0,1176 \\
\hline Negros & 0,6314 & 0,6815 \\
Pardos & 0,2576 & 0,2008 \\
Brancos & 0,1141 & 0,0660
\end{tabular}


Construção

Comércio

Adm. Pública

Serviços
0,2769

0,2640

0,0473

0,3458

Quanto aos setores de atividade, a formalidade está associada principalmente com os serviços (42,87\% dos trabalhadores formais), o comércio $(19,35 \%)$ e a construção (15,38\%). A informalidade, por sua vez, tem sua maior parte distribuída no setor de serviços $(34,58 \%)$, da construção $(27,69 \%)$ e do comércio $(26,40 \%)$. Destaca-se a baixa proporção dos trabalhadores informais inseridos na indústria, cerca de (6,6\%), o que é justificável, já que os vínculos trabalhistas são bastante formalizados na indústria brasileira, nos quais os empregados podem usufruir de direitos como FGTS, seguro desemprego e licença maternidade, por exemplo.

Destaca-se que o setor de serviços concentra a maior parte dos trabalhadores formais e informais sendo que tal resultado corrobora com a análise feita na caracterização socioeconômica de RMB.

A Tabela 2 apresenta a distribuição dos trabalhadores formais e informais da RMB segundo os níveis de rendimento, idade e escolaridade. Para os rendimentos, observa-se que tantos os trabalhadores formais quanto informais concentram-se predominante na faixa de mais de um e até dois salários mínimos, com valores de $49,49 \%$ e $39,74 \%$, respectivamente. Entretanto, tomando os dois extremos da distribuição de rendimentos, percebese diferenciação entre os dois setores, já que enquanto $38,88 \%$ dos trabalhadores informais recebem até um salário mínimo, tal valor para os formais é de $22,91 \%$. Por outro lado, na faixa de rendimento superior a 5 salários mínimos, os resultados se invertem, com o primeiro grupo apresentando valor de 2,87\%, contra 7,64\% do segundo.

Esses resultados em termos de rendimento poderiam também ser indícios de existência de segmentação entre os setores formais e informais do mercado de trabalho na Região Metropolitana de Belém.

Em relação à escolaridade, percebe-se que os trabalhadores informais apresentam percentual maior até no máximo 10 anos de estudo, sendo que a partir dos 11 anos sua contraparte formal é superior.

Tabela 2 - Distribuição dos trabalhadores formais e informais na área urbana da RMB segundo variáveis de interesse, 2013

\begin{tabular}{|c|c|c|c|c|c|c|}
\hline \multirow{2}{*}{ Rendimento } & & $\begin{array}{l}\text { Até } 1 \\
\text { SM }^{*}\end{array}$ & $\begin{array}{c}>1 \text { até } 2 \\
S^{*}\end{array}$ & $\begin{array}{c}>2 \text { até } 3 \\
{S M^{*}}^{*}\end{array}$ & $\begin{array}{c}>3 \text { até } 5 \\
S^{*}\end{array}$ & > $5 \mathrm{SM}^{\star}$ \\
\hline & $\begin{array}{l}\text { Formal } \\
\text { Informal }\end{array}$ & $\begin{array}{l}22,91 \% \\
38,88 \%\end{array}$ & $\begin{array}{l}49,49 \% \\
39,74 \%\end{array}$ & $\begin{array}{r}10,79 \% \\
9,90 \%\end{array}$ & $\begin{array}{l}9,16 \% \\
8,61 \%\end{array}$ & $\begin{array}{l}7,64 \% \\
2,87 \%\end{array}$ \\
\hline \multirow[b]{2}{*}{ Escolaridade } & & $<3$ & 4 a 7 & 8 a 10 & $=11$ & $>11$ \\
\hline & $\begin{array}{l}\text { Formal } \\
\text { Informal }\end{array}$ & $\begin{array}{r}4,78 \% \\
13,77 \%\end{array}$ & $\begin{array}{l}12,21 \% \\
26,11 \%\end{array}$ & $\begin{array}{l}18,02 \% \\
21.66 \%\end{array}$ & $\begin{array}{l}44,40 \% \\
30.13 \%\end{array}$ & $\begin{array}{r}20,57 \% \\
8.32 \%\end{array}$ \\
\hline \multirow[t]{2}{*}{ Idade } & & $\begin{array}{c}24 \text { a } 32 \\
\text { anos }\end{array}$ & $\begin{array}{c}33 \text { a } 40 \\
\text { anos }\end{array}$ & $\begin{array}{c}41 \text { a } 48 \\
\text { anos }\end{array}$ & $\begin{array}{c}49 \text { a } 56 \\
\text { anos }\end{array}$ & $\begin{array}{c}57 \text { a } 65 \\
\text { anos }\end{array}$ \\
\hline & Formal & $31,06 \%$ & $28,41 \%$ & $18,84 \%$ & $14,46 \%$ & 7,23\% \\
\hline
\end{tabular}


Informal $\quad 22,81 \% \quad 22,38 \% \quad 22,24 \% \quad 18,65 \% \quad 13,92 \%$

Fonte: Resultados da pesquisa com base nos dados da PNAD 2013.

* Salário Mínimo vigente a partir de 01/01/2015, no valor de $\mathrm{R} \$ 788,00$.

Quanto à idade dos trabalhadores, não se observou padrão definido de comportamento entre as faixas de idade consideradas, assim como diferença significativa entre elas para os dois setores. Porém, percebe-se que dos 24 aos 40 anos, o setor formal supera o informal, invertendo na faixa dos 41 aos 65 anos. Dessa forma, percebe-se que à medida que o trabalhador torna-se mais velho, a uma tendência a se concentrar mais no setor informal do que no setor formal.

Conforme D'Alencar e Campos (2006), a entrada do idoso no mundo da informalidade é consequência da absoluta necessidade, devido às baixas aposentadorias que são insuficientes para cobrir as despesas, por não ter oportunidade no mercado formal e pelo fato, de que alguns idosos afirmam que o trabalho informal é para não ficar parado e acabar adoecendo. O mesmo autor completa dizendo que os idosos apesar de serem majoritariamente aposentados, a permanência desses idosos no trabalho não significa saída das condições de pobreza em que sempre se encontraram muitas vezes. No entanto, e apesar das dificuldades e do desconforto sob o qual o realizam (jornadas extenuantes, exigência de força física para carregar peso, dentre outros), esse trabalho acaba exercendo um papel socializador importante para essas pessoas, que o vêm como oportunidades de serem úteis, de continuarem interagindo e mantendo as amizades construídas fora do circuito doméstico. Esses fatores contribuem para o aumento da informalidade nessa faixa etária.

\subsection{Retornos do rendimento dos trabalhadores informais e formais da RMB para os diferentes quantis}

Observa-se na Tabela 3 que no intervalo compreendido pelas faixas de 0-14 a 76-90 não foi verificada diferença estatisticamente significativa em termos de rendimentos médios entre os trabalhadores formais e informais. No entanto, no intervalo compreendido pelos quantis 91 obteve-se que os trabalhadores formais apresentaram rendimento médio estatisticamente superior à sua contraparte formal, ao nível de significância de $10 \%$. Sendo que nesse quantil, em média, o setor formal remunerava $R \$ 1.050,83$ a mais do que no caso dos informais, sendo a maior diferença estatisticamente significativa.

Tabela 3 - Média dos valores de rendimentos, em reais, entre diferentes quantis da distribuição para os trabalhadores formais e informais da área urbana da RMB, 2013

\begin{tabular}{|c|c|c|c|c|c|c|c|}
\hline & & Q0-Q14 & $\begin{array}{l}\text { Q15- } \\
\text { Q25 }\end{array}$ & $\begin{array}{l}\text { Q26- } \\
\text { Q50 }\end{array}$ & $\begin{array}{l}\text { Q51- } \\
\text { Q75 }\end{array}$ & $\begin{array}{l}\text { Q76- } \\
\text { Q90 }\end{array}$ & $\begin{array}{l}\text { Q91- } \\
\text { Q100 }\end{array}$ \\
\hline Rendimento & $\begin{array}{l}\text { Formal } \\
\text { Informal }\end{array}$ & $\begin{array}{l}450,00 \\
(35,45) \\
377,27\end{array}$ & $\begin{array}{r}673,38 \\
(2,13) \\
611,76\end{array}$ & $\begin{array}{r}791,68 \\
(5,60) \\
774,51\end{array}$ & $\begin{array}{r}1.252,62 \\
(10,37) \\
1.212,39\end{array}$ & $\begin{array}{r}2.226,07 \\
(33,17) \\
2.234,17\end{array}$ & $\begin{array}{l}6.081,38 \\
(425,38) \\
5.030,55\end{array}$ \\
\hline
\end{tabular}


Nota: desvio-padrão entre parênteses.

$(11,91) \quad(6,00)$

$(5,98)$

$(14,69)$

$(40,47)$

$(516,42)$

Fonte: Resultados da pesquisa com base nos dados da PNAD 2013.

As Tabelas 4 e 5 apresentam os testes de igualdade interquantil proposto por Wald, o qual direcionou os resultados das regressões quantílicas, verificando se de fato, os coeficientes das equações de rendimento diferem entre os quantis, justificando assim, o uso do modelo de regressão quantílica. Para os trabalhadores formais, os coeficientes das variáveis de escolaridade para maiores que 11 anos de estudo e raça (negros) mostraram-se estatisticamente diferentes entre os quantis da distribuição. Já, para os trabalhadores informais apenas os coeficientes da variável escolaridade para maiores que 11 anos foi estatisticamente diferente entre os quantis. Esse resultado indicaria o uso da estimativa dos rendimentos médios através do método clássico de regressão linear. Entretanto, para manter o mesmo tipo de estimação entre os dois setores, possibilitando o modelo de Koenker e Basset (1978) no contexto quantílico, manteve-se a estimação de regressões quantílica.

Tabela 4 - Teste das médias dos valores de rendimentos, em reais, para diferentes quantis da distribuição entre os trabalhadores formais e informais da área urbana da RMB, 2013.

\begin{tabular}{ccc}
\hline Setor & \multicolumn{2}{c}{ Informal/Formal } \\
\hline $\begin{array}{c}\text { Quantis da distribuição } \\
\text { de rendimento }\end{array}$ & \multicolumn{2}{c}{ Teste das } \\
Estat. t & Valódias \\
\hline Q0-Q14 & $-1,96$ & 0,052 \\
Q15- Q25 & $-9,40$ & 0,000 \\
Q26-Q50 & $-1,93$ & 0,055 \\
Q51-Q75 & $-2,24$ & 0,026 \\
Q76-Q90 & 0,16 & 0,876 \\
Q91-Q100 & $-1,54$ & 0,124 \\
\hline Fonte: Resultados da pesquisa com base nos dados da PNAD 2013.
\end{tabular}

Tabela 5 - Testes de igualdade interquantil para os trabalhadores formais e informais, área urbana da RMB, 2013.

\begin{tabular}{lcccc}
\hline Setores & Formal & \multicolumn{3}{c}{ Informal } \\
\hline Variáveis & Estatística & Prob. & Estatística F & Prob. \\
\hline
\end{tabular}




\begin{tabular}{lcccc}
\hline E2 (4 a 7 anos) & 0,38 & 0,6861 & 1,61 & 0,2011 \\
E3 (8 a 10 anos) & 0,98 & 0,3771 & 0,05 & 0,9489 \\
E4 (11 anos) & 1,94 & 0,1438 & 1,78 & 0,1689 \\
E5 ( > 11 anos) & 11,83 & 0,0000 & 2,49 & 0,0839 \\
Idade & 0,72 & 0,4894 & 0,99 & 0,3726 \\
Idade $^{2}$ & 0,63 & 0,5328 & 0,73 & 0,4816 \\
Negros & 5,15 & 0,0060 & 1,65 & 0,1927 \\
Pardos & 1,25 & 0,2858 & 0,55 & 0,5755 \\
Construção & 1,19 & 0,3036 & 1,60 & 0,2032 \\
Comércio & 0,31 & 0,7306 & 0,11 & 0,8980 \\
Adm. Pública & 0,26 & 0,7675 & 1,64 & 0,1947 \\
Serviços & 0,24 & 0,7853 & 0,38 & 0,5837 \\
\hline \multicolumn{1}{l}{ Fon }
\end{tabular}

Fonte: Resultados da pesquisa.

Para iniciar a discussão econômica dos resultados para os trabalhadores formais, apresenta-se, na Tabela 6 , as estimativas das equações mincerianas para os diferentes quantis da distribuição de rendimentos.

Tabela 6 - Resultados da regressão quantílica para os trabalhadores formais da RMB, 2013

\begin{tabular}{lccc}
\hline & Q10 & Q50 & Q90 \\
\hline E2 (4 a 7 anos) & $-0,0842$ & $-0,0005$ & $-0,1603$ \\
& $(0,0634)$ & $(0,1234)$ & $(0,1856)$ \\
E3 (8 a 10 anos) & $-0,0049$ & 0,1686 & 0,1148 \\
& $(0,0621)$ & $(0,1184)$ & $(0,1769)$ \\
E4 (11 anos) & $0,0979^{*}$ & $0,3345^{* *}$ & $0,3174^{* *}$ \\
& $(0,0591)$ & $(0,1125)$ & $(0,1681)$ \\
E5 ( $>11$ anos) & $0,4262^{* *}$ & $1,0134^{* *}$ & $1,4264^{* *}$ \\
& $(0,0651)$ & $(0,1202)$ & $(0,1818)$ \\
Idade & $-0,0010$ & 0,0170 & $-0,0085$ \\
& $(0,0090)$ & $(0,0170)$ & $(0,0267)$ \\
Idade 2 & 0,0000 & 0,0000 & 0,0004 \\
& $(0,0001)$ & $(0,0002)$ & $(0,0003)$ \\
Negros & $-0,0357$ & $-0,2312^{* * *}$ & $-0,3153^{* * *}$ \\
& $(0,0444)$ & $(0,0831)$ & $(0,1306)$ \\
Pardos & $-0,0089$ & $-0,0891^{\star}$ & $-0,1151$ \\
& $(0,0291)$ & $(0,0541)$ & $(0,0902)$ \\
Construção & $0,0992^{* *}$ & 0,0420 & $-0,2182$ \\
& $(0,0495)$ & $(0,0910)$ & $(0,1523)$
\end{tabular}




$\begin{array}{lccc}\text { Comércio } & -0,0757^{*} & -0,1026 & -0,2305^{\star} \\ & (0,0459) & (0,0864) & (0,1433) \\ \text { Adm. Pública } & 0,3038^{* \star *} & 0,3963^{\star * \star} & 0,4402^{* \star *} \\ & (0,0525) & (0,0991) & (0,1664) \\ \text { Serviços } & 0,0142 & 0,0221 & -0,1087 \\ & (0,0404) & (0,0769) & (0,1270) \\ \text { Constante } & 1,1693^{\star \star \star} & 0,9586^{\star * \star} & 2,1291^{\star \star \star} \\ & (0,2106) & (0,3672) & (0,5551)\end{array}$

${ }^{* * *}$ Significativo a $1 \%$; ${ }^{* *}$ Significativo a $5 \%$, ${ }^{*}$ Significativo a $10 \%$. Desvio-padrão obtido por bootstrap com 50 repetições.

Fonte: Resultados da pesquisa

Ao analisar as variáveis de estudo, em relação a variável escolaridade, observou-se que a mesma relaciona-se positivamente com o rendimento do trabalhador formal. Tal relação direta para todos os quantis é percebida apenas a partir de 11 anos de estudos. Em todos os quantis, os indivíduos que tinham pelo menos o ensino médio (11 anos de estudo) e anos de ensino superior (mais de 11 anos de estudo) apresentaram maiores ganhos de rendimento em comparação àqueles que tinham 10 ou menos anos de estudo.

Comparando os efeitos marginais das variáveis de escolaridade entre os diferentes quantis, observa-se pelos gráficos 4 e 5 da Figura $1^{7}$, que os retornos para a escolaridade são crescentes à medida que se elevam os quantis de rendimento. Este resultado indica não somente que, conforme a teoria do capital humano, a escolaridade é um investimento que gera retorno em termos de renda mais elevada para os indivíduos, mas também que tal ganho é ainda mais significativo nos níveis de rendimento do trabalho mais elevado.

${ }^{7} \mathrm{~A}$ Figura 1 apresenta graficamente os coeficientes estimados e sua comparação com uma estimação de Mínimos Quadrados Ordinários (MQO), representado pelas linhas horizontais cheias, com as linhas pontilhadas representando o seu intervalo de confiança. 

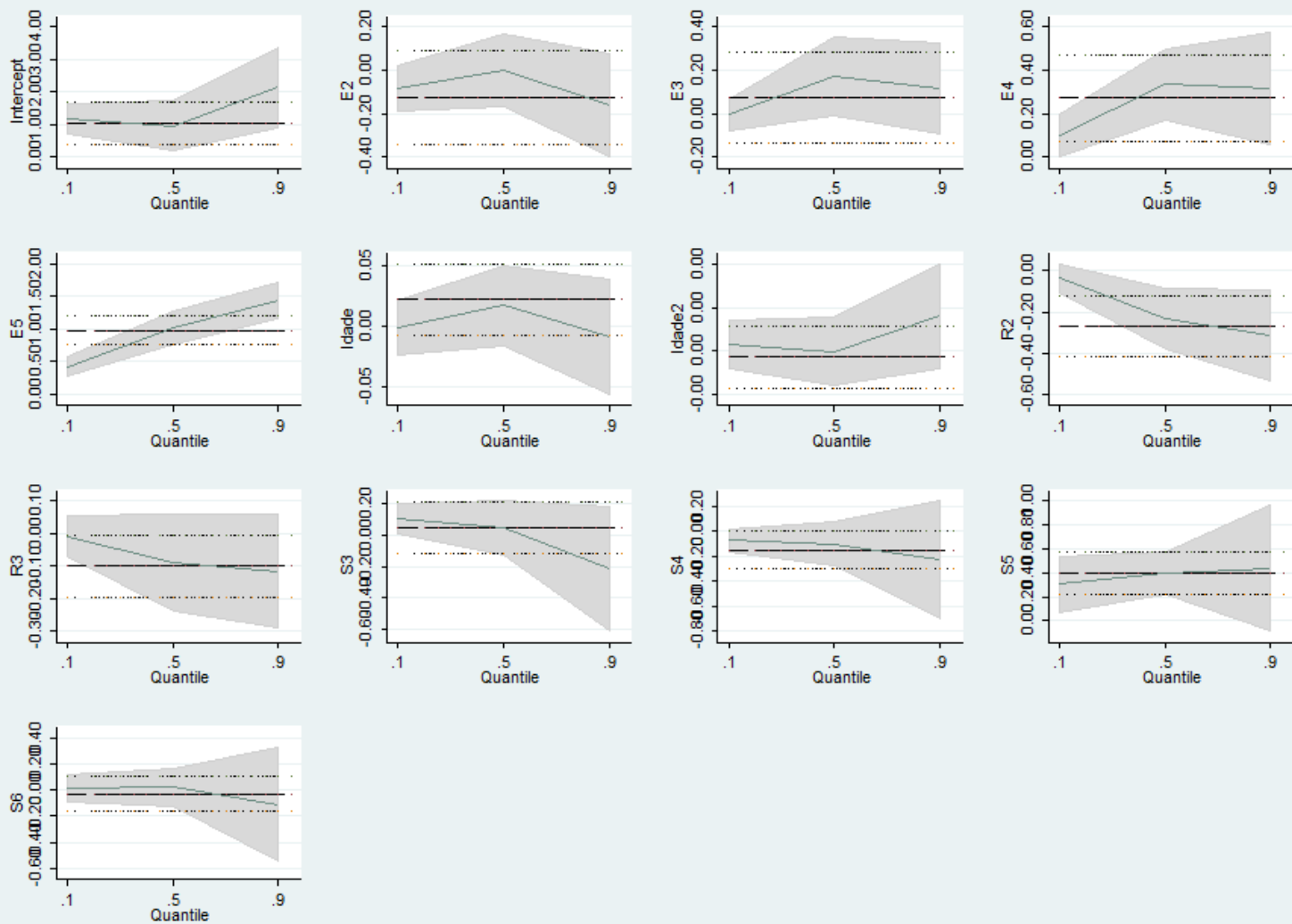

Figura 1 - Coeficientes das regressões quantílicas para os trabalhadores formais da área urbana da RMB, 2013.

Fonte: Resultado da pesquisa.

Tratando-se da idade, verifica-se que a mesma não foi estatisticamente significativa em nenhum quantil da distribuição de rendimento.

Com relação a variável raça, notou-se que os rendimentos para negros e pardos foi relativamente menor do que aquele percebido pelos brancos. Temse que a variável negros foi estatisticamente significativa, ao nível de significância de $1 \%$, nos quantis 50 e 90 . Já a variável pardos foi estatisticamente significativa, ao nível de significância de $10 \%$, no quantil 50 .

Verifica-se que a desvantagem dos pardos e dos negros em relação aos brancos aumenta à medida que os quantis de rendimento crescem. Isso pode ser visto no gráfico 8 e 9 da Figura 1, nos quais tem-se que os coeficientes associados principalmente a variável negros tornam-se cada vez mais negativos para os quantis superiores da distribuição.

Em relação às variáveis de setor econômico, não se verificou padrão homogêneo para todos os quantis da distribuição de rendimento. $\mathrm{Na}$ construção civil, verifica-se para o $10^{\circ}$ quantil um rendimento $9,92 \%$ superior em relação ao setor base (indústria). Para o comércio, verificou-se para o 10응 quantil um rendimento de $7,57 \%$ e para o $90^{\circ}$ um rendimento de $23,05 \%$ inferior à indústria. Quanto à administração pública, verifica-se um rendimento superior em relação à indústria em todos os quantis, sendo que tal diferença foi crescente quando se movia da base para o topo da distribuição de rendimentos, atingindo seu valor máximo de $44,02 \%$ no quantil 90 . Quanto ao 
setor de serviços, nota-se que para todos os quantis, tal diferença não foi estatisticamente significativa.

Passando agora dos resultados das regressões quantílicas para os trabalhadores informais (Tabela 7). Quanto à escolaridade, assim como já ocorrera entre os trabalhadores formais, observou-se dentro de cada quantil, relação direta entre o rendimento e os anos de estudo, confirmando novamente a teoria do capital humano.

Tabela 7 - Resultados da regressão quantílica para os trabalhadores informais da RMB, 2013

\begin{tabular}{|c|c|c|c|}
\hline & Q10 & Q50 & Q90 \\
\hline E2 (4 a 7 anos) & $\begin{array}{l}0,3022^{* \star \star} \\
(0,1099)\end{array}$ & $\begin{array}{c}0,1272 \\
(0,0849)\end{array}$ & $\begin{array}{c}0,2890^{*} \\
(0,1628)\end{array}$ \\
\hline E3 (8 a 10 anos) & $\begin{array}{l}0,3189^{* * *} \\
(0,1181)\end{array}$ & $\begin{array}{l}0,3274^{* * *} \\
(0,0892)\end{array}$ & $\begin{array}{l}0,3703^{* *} \\
(0,1749)\end{array}$ \\
\hline E4 (11 anos) & $\begin{array}{l}0,3590^{* * \star} \\
(0,1114)\end{array}$ & $\begin{array}{l}0,3027^{\star \star \star} \\
(0,0851)\end{array}$ & $\begin{array}{l}0,5611^{\star \star \star} \\
(0,1674)\end{array}$ \\
\hline E5 ( > 11 anos) & $\begin{array}{l}0,5720^{* \star \star} \\
(0,1529)\end{array}$ & $\begin{array}{l}0,8055^{* \star *} \\
(0,1158)\end{array}$ & $\begin{array}{l}1,2053^{\star \star \star} \\
(0,2201)\end{array}$ \\
\hline Idade & $\begin{array}{c}0,0199 \\
(0,0262)\end{array}$ & $\begin{array}{l}0,0550 \\
(0,0190)\end{array}$ & $\begin{array}{c}0,0546 \\
(0,0345)\end{array}$ \\
\hline Idade ${ }^{2}$ & $\begin{array}{l}-0,0001 \\
(0,0002)\end{array}$ & $\begin{array}{c}-0,0005^{\star \star \star} \\
(0,0002)\end{array}$ & $\begin{array}{c}-0,0004 \\
(0,0003)\end{array}$ \\
\hline Negros & $\begin{array}{c}0,0720 \\
(0,1257)\end{array}$ & $\begin{array}{l}-0,0409 \\
(0,0939)\end{array}$ & $\begin{array}{l}-0,2617 \\
(0,1829)\end{array}$ \\
\hline Pardos & $\begin{array}{c}0,0538 \\
(0,0843)\end{array}$ & $\begin{array}{c}0,0458 \\
(0,0651)\end{array}$ & $\begin{array}{l}-0,0436 \\
(0,1262)\end{array}$ \\
\hline Construção & $\begin{array}{c}0,1436 \\
(0,1421)\end{array}$ & $\begin{array}{l}-0,0518 \\
(0,1108)\end{array}$ & $\begin{array}{l}-0,4471^{*} \\
(0,2082)\end{array}$ \\
\hline Comércio & $\begin{array}{c}-0,1602 \\
(0,1446)\end{array}$ & $\begin{array}{l}-0,0819 \\
(0,1107)\end{array}$ & $\begin{array}{l}-0,0050 \\
(0,2086)\end{array}$ \\
\hline Adm. Pública & $\begin{array}{l}0,5259^{\star * \star} \\
(0,2021)\end{array}$ & $\begin{array}{l}0,6983^{\star \star \star} \\
(0,1547)\end{array}$ & $\begin{array}{c}0,1499 \\
(0,2596)\end{array}$ \\
\hline Serviços & $\begin{array}{c}0,2012 \\
(0,1403)\end{array}$ & $\begin{array}{c}0,0317 \\
(0,1082)\end{array}$ & $\begin{array}{c}0,0489 \\
(0,2025)\end{array}$ \\
\hline Constante & $\begin{array}{c}0,0979 \\
(0,5699)\end{array}$ & $\begin{array}{c}0,0716 \\
(0,4246)\end{array}$ & $\begin{array}{c}0,9004 \\
(0,7780)\end{array}$ \\
\hline
\end{tabular}

${ }^{* * *}$ Significativo a 1\%; ** Significativo a 5\%, Significativo a 10\%. Desvio-padrão obtido por bootstrap com 50 repetições.

Fonte: Resultados da pesquisa

Para os quantis 10 e 90, tal relação ocorre para todas as variáveis qualitativas, para o quantil 50 tal relação direta é percebida apenas a partir de 8 anos de estudos. $\mathrm{Na}$ comparação dos coeficientes das variáveis de escolaridade entre os setores formal e informal, teve-se que para aquela representando 11 anos ou mais de estudo, o efeito marginal foi maior para 0 primeiro setor para todos os quantis, exceto o 10․ Tal resultado indica então que os ganhos proporcionados por anos de ensino superior tendem a serem maiores no setor formal do que no informal. Por outro lado, para a variável de ensino médio o resultado foi contrário, ou seja, maiores ganhos para os 
informais em comparação aos formais, exceto no $50^{\circ}$ quantil. A informalidade fornece ganhos mais imediatos aos primeiros anos de estudo, conforme pode ser visto no $10^{\circ}$ quantil, para a variável E2.

Tratando-se da idade, uma vez que foi entendida como uma proxy da experiência $^{8}$ de trabalho, verifica-se que a mesma foi estatisticamente significativa apenas no quantil 50 da distribuição de rendimentos. Tem-se que para este quantil, o aumento em 1 ano da idade do trabalhador, aumentaria seu rendimento em média em $5,50 \%$, ceteris paribus.

Quanto a variável raça, nota-se que a mesma não foi estatisticamente significativa em nenhum quantil da distribuição de rendimentos. Quanto ao setor econômico, os trabalhadores informais da construção apresentaram rendimento inferior de $44,71 \%$ no $90^{\circ}$ quantil em relação à base (indústria). $\mathrm{Na}$ administração pública, nos quantis 10 e 50, verifica-se um rendimento superior de $52,59 \%$ e $69,83 \%$, respectivamente, em relação ao setor base. Para os demais setores econômicos, os resultados não foram estatisticamente diferentes de zero para os trabalhadores informais.

\section{Considerações Finais}

O debate a respeito da existência ou não de uma dualidade formalinformal no mercado de trabalho brasileiro e de suas possíveis implicações é bastante extenso, como reflexo das diferentes visões e resultados encontrados por diversos autores. Dentro desse contexto e diante da carência de estudos de caráter mais regional, o presente trabalho procurou investigar a ocorrência o diferencial de rendimento entre trabalhadores formais e informais para homens do mercado de trabalho urbano da RMB.

Em relação ao modelo de regressão quantílica, observou-se tanto para os trabalhadores formais quanto para os informais, a relevância da variável educação como importante determinante para o rendimento do trabalho, ou seja, quanto maiores os anos de estudo maiores esse último. Para os trabalhadores formais destacou-se ainda a existência de discriminação racial no mercado de trabalho analisado, sendo que a mesma mostrou-se maior para os níveis mais elevados de rendimento. Tal resultado sugere a existência de um "teto de vidro" impedindo a ascensão de trabalhadores negros e pardos ao topo dos níveis de rendimento no setor formal.

$\mathrm{Na}$ comparação entre os dois setores, para a variável escolaridade verificou-se, de maneira geral, para os trabalhadores formais, maior retorno de rendimento para 11 anos ou mais de estudo. Tal resultado indica que os ganhos proporcionados por anos de ensino superior tendem a serem maiores no setor formal do que no informal. Por outro lado, para a variável de ensino médio o resultado foi contrário, ou seja, maiores ganhos para os informais em

\footnotetext{
8 Para mensurar a variável experiência da equação minceriana, normalmente a literatura do capital humano emprega uma proxy: $\mathrm{j}=$ idade $-\mathrm{s}-6$. Conforme Chaves (2002), essa proxy para a equação minceriana tem como hipótese que o indivíduo começa a trabalhar logo após terminar seus anos de estudo, e que esse termina o período escolar no tempo $s$ mais seis anos de idade, em que esse último é a idade em que o indivíduo, em média, começa a estudar.
} 
comparação aos formais. Quanto à variável idade, mostrou-se pouco significativo para os trabalhadores formais e informais da Região Metropolitana de Belém.

Como sugestão para trabalhos futuros, propõe-se estudo mais pormenorizado do mercado de trabalho da RMB, de forma a mapear de maneira mais precisa o setor informal dessa economia, permitindo então, explicações adicionais acerca do diferencial de rendimento desse setor em relação ao formal.

\section{Referências}

BORJAS, G.J.; MINCER, J. The distribution of earnings profiles in longitudinal data. NBER Working Paper, n. 143, 1976.

CACCIAMALI, M C. Globalização e processo de informalidade. Economia e Sociedade, IE - UNICAMP, São Paulo, julho, p. 153-175, 2000.

CARNEIRO, F.G.; HENLEY, A. Modelling formal vs. informal employment and earnings: micro-econometric evidence for Brazil. Encontro Nacional de Economia. Anais. ANPEC, 2001.

CIRINO, Jader Fernandes; LIMA, Joao Eustaquio de. Diferenças de Rendimento entre as Regiões metropolitanas de Belo Horizonte e Salvador: uma discussão a partir da decomposição de Oaxaca-Blinder. REN. Revista Economica do Nordeste, v. 43, n. 2, p. 371-389, 2012.

DALBERTO, C.R. Formalidade vs. Informalidade no mercado de trabalho brasileiro: uma investigação dos diferenciais de rendimento. Viçosa, MG: UFV, 2014. 87 f. Dissertação (Mestrado em Economia) - Programa de PósGraduação em Economia da Universidade Federal de Viçosa. Viçosa, 2014.

D'ALENCAR, R. S; CAMPOS, J. B. VELHICE E TRABALHO: a informalidade como (re) aproveitamento do descartado. Revista Estud. interdiscip. envelhec., Porto Alegre, v. 10, p. 29-43, 2006.

FERREIRA, J.C. O Pará e seus Municípios. Belém: J.C..V Ferreira, 2003.

FERREIRA, Maria da Luz Alves. Trabalho Informal e Cidadania: heterogeneidade social e relações de gênero. Tese de doutorado em Ciências Humanas - Sociologia e 19 Política. Faculdade de Filosofia e Ciências Humanas. Universidade Federal de Minas Gerais, Belo Horizonte, 2007.

INSTITUTO BRASILEIRO DE GEOGRAFIA E ESTATÍSTICA - IBGE. (2015). Cidades. Disponível em: <http://www.cidades.ibge.gov.br/xtras/home.php>. Acesso em: 21 out. 2015

KOENKER, R.; BASSET, G. Regressions quantiles. Econometrica, v. 1, n. 46, 
p. 33-50, 1978.

MACHADO, A.F.; OLIVEIRA, A.M.H.C.; ANTIGO, M. Evolução do diferencial de rendimentos entre setor formal e informal no Brasil: o papel das características não observadas. Revista de Economia Contemporânea, v. 12, n. 2, p. 355-388, 2008.

MENEZES-FILHO, N.A.; MENDES, M.; ALMEIDA, E.S. 0 diferencial de salários formal-informal no Brasil: segmentação ou viés de seleção? Revista Brasileira de Economia, v. 58, n. 2, p. 235-248, 2004.

MTE. A informalidade no mercado de trabalho brasileiro e as políticas públicas do governo federal. Observatório do Mercado de Trabalho do Ministério do Trabalho e Emprego (MTE). Salvador, BA. 2002. Disponível em: $<$ http://portal.mte.gov.br/data/files/FF8080812BA5F4B7012BABBAC51731E4/ln formalidade2.pdf >. Acesso em: 13 mar. 2015.

ORGANIZAÇÃO INTERNACIONAL DO TRABALHO - OIT. Employment, incomes and equality: a strategy for increasing productive employment in Kenya. Geneva: ILO, 1972.

PASTORE, José. Informalidade, estragos e soluções. Congresso do Coppead. Rio de Janeiro, (2004).

PEREIRA, A.M; SILVA, R.S; SILVA, P.R. Desigualdades na informalidade: uma análise das Regiões Nordeste e Sudeste do Brasil. Revista Desenvolvimento Social. Edição Especial, 2014. (ISSN 2179-6807).

PIANTO, MARIA E. TANNURI; AND PIANTO, DONALD M.: "Informal Employment in Brazil - A Choice at the Top and Segmentation at the Bottom: A Quantile Regression Approach", Texto para discussão no 236. Brasília, agosto de 2002.

RODRIGUES, C. I; BORGES, M. T. Economia informal no bairro do Jurunas, Belém-PA. 28ª Reunião Brasileira de Antropologia. São Paulo, 2012. 